of this species on the French coast ${ }^{1}$, informed me in 1945 that he thought this species might have 'crossed the Channel' and invaded the south coasts of England and Ireland because of its abundance on the coast of Brittany. Plants up to five years old are now present in Plymouth Sound; but it is not known how long this species has been there. It was almost cer. tainly not present up to 1900 , otherwise it would have been recognized and recorded by Prof. T. Johnson $^{2}$, who made an intensive study of the marine algæ of Plymouth Sound during 1885-1900. I would, therefore, be grateful for any records of the occur. rence of this species on the cossts of Britain, so that its distribution or its rate of migration can be followed.

Laboratory, Citadel Hill,

Plymouth. July 17.

' Lami, R., Bull. Lab. Marit. Dinard, 25, 19 (1943).

'Johnson, T., J. Mar. Biol. Assoc., 1, 286 (1900).

\section{Insecticidal Power and Microscopical Structure of Residual Films of Benzene Hexachloride}

IN some recent experiments with samples of the $\gamma$-isomer of benzene hexachloride $(1,2,3,4,5,6$-hexachlorocyclohexane), in which adult beetles of Dermestes maculatus Deg. were tested on residual films prepared on glass plates by a recently devised method ${ }^{1}$, it was found that in films formed from chloroform solutions, a certain sample of 'technical' grade material (I) was more insecticidal than the corresponding 'refined' sample (II) and 'refined' (III) and 'technical' (IV)

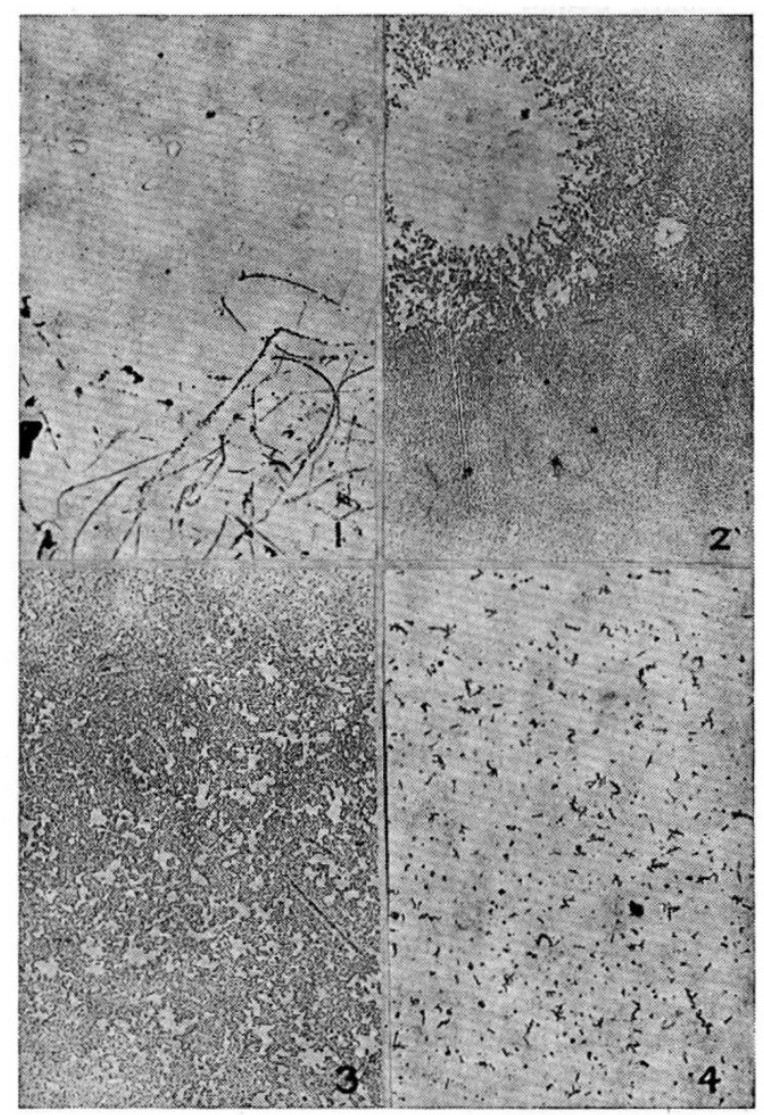

samples of different manufacture. These unexpected observations were the reverse of those obtained by other investigators testing the same samples by different methods ${ }^{2}$. Furthermore, when residual films of the insecticides in a light, refined paraffin spray oil were prepared and tested in this laboratory, samples (II) and (III) were at least as toxic as (I).

A microscopical examination of the chloroform films showed that those prepared from sample (I) were different from the others. After a few hours films of (II), (III) and (IV) had crystallized (Figs. 2, 3 and 4), whereas those of (I), prepared at the same time, under the same conditions, had not: the film was present in the form of discrete globules (Fig. 1, upper). These globules crystallized after insects had walked on them (Fig. 1, lower). Unfortunately, because of the high volatility of benzene hexachloride and the resulting short life of the films, it has not so far been possible to obtain crystals in chloroform films of $(\mathrm{I})$ in any other way. Examination of residual films resulting from light paraffin solutions, where crystallization was considerably retarded in every case, showed that films of samples (I) and (IV) were most retarded.

It is of interest to compare these observations with those of Parkin and Green ${ }^{3}$, who found, however, that crystallization of globule films of D.D.T. resulted in increased toxicity.

At this juncture no full explanation of my observations can be offered. It seems reasonable to suggest, however, that the unexpectedly high toxicity of sample (I) is not entirely due to an impurity, but may be associated with traces of chloroform retained by the film. The matter is being further investigated.

Thanks are due to Dr. R. A. E. Galley for supplying nformation, and to the Council of this Research Association for permission to publish.

British Leather Manufacturers'

A. J. Musgrave

Research Association,

1-6 Nelson Square,

London, S.E.1.

June 17.

${ }^{1}$ Turner, J. N. (in the press).

'Galley, R. A. E. (personal communication).

${ }^{3}$ Parkin, A. E., and Green, A. A., Nature, 155, 668 (1945).

\section{Synthesis of I-Sparteine}

IN view of the synthesis of $d l$-sparteine reported by Leonard and Beylen', we wish to place on record that some time ago we effected the reduction of $l$-oxysparteine to $l$-sparteine by treatment with lithium-aluminium hydride. Full details of this work will be published elsewhere in due course.

Since the total synthesis of $d l$-oxyspartein $e^{2}$, the resolution of $d l$-lupanin $e^{3}$, the transformation of this and its $d$-component into $d l$ - and $l$-sparteine respectively ${ }^{3,4}$ and the oxidation of $d l$-sparteine to dl-oxysparteine ${ }^{4}$ bave been accomplished in these laboratories, the structure of $l$-sparteine is now completely established.

\section{G. R. Cremo \\ R. RAPER \\ W. SHORT}

University of Durham, King's College,

Newcastle-on-Tyne. July 19.

${ }^{1} J$. Amer. Chem. Soc., 70, 2298 (1948).

Clemo, Morgan and Raper, J. Chem. Soc., 1025 (1936).

${ }^{3}$ Clemo, Raper and Tenniswood, J. Chem. Soc., 429 (1931).

- Clemo and Leitch, J. Chem. Soc., 1811 (1928). 